\title{
ORIGINAL RESEARCH \\ Factors Affecting the Implementation and Barriers to Evidence-Based Practice among Nurse Practitioners in Hail Region, Saudi Arabia
}

\author{
Majed Shafi Alshammari ${ }^{1}$, Raad Alshurtan², Gadah Alsuliman², Marzoogha Alshammari², \\ Housam Alhamazani ${ }^{2}$, Samiha Alshammry ${ }^{2}$, Richard Dennis Dayrit ${ }^{1}$, Mohannad Alkwiese ${ }^{1}$ \\ ${ }^{1}$ Department of Nursing, University of Hail, Saudi Arabia \\ ${ }^{2}$ Hail General Hospital, Ministry of Health, Saudi Arabia
}

\begin{tabular}{l} 
Article Info \\
\hline Article History: \\
Received: 8 May 2021 \\
Revised: 16 July 2021 \\
Accepted: 18 July 2021 \\
Online: 27 August 2021 \\
Keywords: \\
Evidence-based practice; nurse \\
practitioners; perceptions; quality \\
of healthcare; Saudi Arabia \\
Corresponding Author: \\
Majed Shafi Alshammari \\
Department of Nursing, University \\
of Hail, Saudi Arabia \\
Email: uohteam2020@gmail.com
\end{tabular}

Email: uohteam2020@gmail.com

\begin{abstract}
Background: While previous studies explored the implementation and barriers to evidence-based practice (EBP), there is a dearth of literature on the causative factors such as demographics that affect the implementation and barriers to EBP.

Purpose: This study aimed to investigate the factors affecting the implementation of EBP and determine its barriers as perceived by nurse practitioners.

Methods: This study employed a quantitative correlational design. A total of 228 staff nurses from the hospitals in the Hail region, Saudi Arabia, participated in this study through purposive sampling. The evidence-based practice questionnaire (EBPQ) and the barriers scale questionnaire were used to collect the data between June and July 2020. The descriptive statistics, t-test, and analysis of variance (ANOVA) were used to analyze the collected data.

Results: The nurses showed a positive attitude ( $x=15.25 \pm 5.07)$, good knowledge $(x=63.44 \pm 19.81)$, as well as good application of EBP $(x=28.02 \pm 6.68)$ with an outstanding EBP score of 106.73 out of 168 . Nurses' civil status $(p<0.02)$, nationality $(p<0.05)$, highest degree $(p<0.01)$, job title $(p<0.001)$, and years of experience $(p<0.001)$ significantly affected the implementation of EBP. Also, the biggest barriers to EBP were: "No time to read research" (94.3\%), "Research is not readily available" (97.8\%), "Not capable to evaluate the quality of research" (90.4\%), and "Uncertain whether to believe results" (68.4\%).

Conclusion: Nurses have a positive attitude, good knowledge, and good application of EBP. Civil status, nationality, highest degree, job title, and years of experience were causative factors to EBP. Nurses in hospitals should undergo training continuously to be able to use EBP effectively.
\end{abstract}

How to cite: Alshammari, M. S., Alshurtan, R., Alsuliman, G., Alshammari, M., Alhamazani, H., Alshammry, S., Dayrit, R. D., \& Alkwiese, M. (2021). Factors affecting the implementation and barriers of evidence-based practice among nurse practitioners in Hail region, Saudi Arabia. Nurse Media Journal of Nursing, 11(2), $187-196$. https://doi.org/10.14710/nmjn.v11i2.38329

\section{Introduction}

Evidence-based practice (EBP) in healthcare can improve the expected quality of care, thus reducing the disparity in giving care and cost (Melnyk \& Fineout-Overholt, 2015; Melnyk et al., 2012). As such, healthcare providers, despite their complex roles, are expected to implement EBP for better outcomes in healthcare. From its former definition of using the present findings to decide which patient care is best (Sackett, 2000), the concept of EBP has been expanded to include a lifelong problem-solving approach in how healthcare is delivered, and this integrates the best evidence from high-quality studies, such as the clinician's expertise, patient's preferences, and their values (Melnyk \& Fineout-Overholt, 2015).

Research suggests that nurses are not prepared to adopt EBP and rarely employ innovative knowledge (Renolen et al., 2018; Stokke et al., 2014), which could be due to several underlying factors and barriers. These factors and barriers could fetter their adoption, leaving the nurses unmotivated to implement EBP. Some of the most documented barriers for nurses in using EBP are negative perceptions, time inadequacy, and lack of knowledge and skills (Mallion \& Brooke, 2016). Therefore, addressing these problems is assumed to influence the nurses to use EBP in their profession. Indeed, when supported by nursing education and their organizations, nurses can apply EBP (Ozdemir \& Akdemir, 2009), and thus nursing leadership is contributory to EBP 
application (Harper et al., 2017). Equally, the implementation of EBP is complemented by effective execution and enabling context (Chien, 2019).

Earlier studies have explored the implementation and barriers of EBP. For example, Stokke et al. (2014) found that nurses lack familiarity concerning the principles of EBP, thereby employing EBP to a lesser extent. Further, the lack of time, skills, motivation to evaluate research and implementing the results in practice were found as barriers to EBP implementation (Chummum \& Tiran, 2008), which can transpire equally at the level of individual and organization (Khammarnia et al.,2015). While previous studies explored the implementation and barriers to EBP, there is a dearth of literature on the causative factors such as demographics that affect the implementation and barriers. For instance, Dalheim et al. (2012) found that the lack of time, unhelpful physicians, limited resources, and lack of access to information were the major hurdles highlighted in their investigation. While nurses are in a unique position to promote and support EBP in clinical settings, they have the opportunity to enhance their knowledge and skills (Malik et al., 2015). However, nurses face many challenges in EBP application, and thus, factors influencing EBP implementation need to be evaluated (Farokhzadian et al., 2015). To Swito et al. (2021), the use of evidence-based practice (EBP) as an ideal problem-solving strategy was one of the elements in improving the quality of health services, and this has been influenced by a number of factors (e.g., support of nurses' unit leader and colleagues). Moreover, there has not been any study in the Hail region of Saudi Arabia that has researched the barriers to the implementation of EBP. However, some scholars have indicated that nurses may vary in their preparation for evidence-based practice (Saunders et al., 2016), despite recommendations from research findings.

Addressing the changing demographics in the nursing profession can be assumed as key to implementation and reconciling the barriers. Exploring the barriers to EBP among nurse practitioners lays the groundwork for nursing leaders to create strategies to help nurses toward effective implementation of EBP; when implemented, the safety and quality of healthcare are ensured. This study aimed to investigate the causal factors that affect the implementation of EBP and determine its barriers as perceived by nurse practitioners.

\section{Methods}

2.1 Research design

This study employed a quantitative cross-sectional approach to determine the causal factors that affect the implementation of EBP and its barriers as perceived by nurse practitioners.

\subsection{Setting and samples}

This study was conducted among nurses from the hospitals in the Hail region, Kingdom of Saudi Arabia. The number of samples was determined through the Raosoft sample size online calculator (Raosoft, 2004) using a 95\% confidence level. The inclusion criteria were set to nurses who (a) had undergone EBP workshop training as part of their continuing professional development; (b) could understand and write English; (c) and joined the orientation for this study. The exclusion criteria included the following; (a) nurses who were newly hired before the data gathering, and (b) nurses who were absent or on leave during the time of data gathering. The purposive sampling was used with the consideration that participants in the study started implementing the EBP in their units. Of the 237 distributed questionnaires, only 228 participants returned the completed questionnaires resulting in a $96.2 \%$ response rate.

\subsection{Measurement and data collection}

A survey using Google Forms was used to collect the data. Prior to data collection, an orientation to the participants was conducted to explain and inform them about the study, expectations, study purpose, risk and benefits, and voluntary participation. The orientation was personally conducted by the researchers per unit of the hospitals. The Google link was sent to the head nurses of each unit of the participating hospitals. The head nurses, in turn, sent the link to those staff nurses who had started implementing EBP in their unit. The data were collected between 20 June and 30 July 2020.

The Evidence-Based Practice Questionnaire (EBPQ) by Upton and Upton (Upton \& Upton, 2006) and the barriers scale by Funk et al. (1991) were used in this study with their permission. The EBPQ consists of a 24-item statement with three subscales rated on a seven-point Likert scale 
with responses ranging from 1 (poor/never) to 7 (best/frequently). The attitude has 4 items with a minimum score of 1 and a maximum score of 28, knowledge with 14 items having 1 as the minimum and 98 as maximum scores, and use of EBP with 6 items with 1 as minimum and 42 as the maximum scores. The rating is computed by adding the response value of each question with 168 as the overall score. According to Upton and Upton (2006), higher score indicates a more positive attitude toward EBP as well as better use and knowledge of EBP. The item in the attitudes had a couple of opposing statements with a negative and a corresponding positive statement. Using these statements, the respondents were asked to rank their attitudes toward EBP. Accordingly, if the score was greater than four, the response was deemed positive.

The barrier scale comprises 29 items with 4 characteristics, including (a) organizational characteristics with 8 items, (b) characteristics of the adopter with 8 items, (c) characteristics of communication with 6 items, and (d) characteristics of innovation with 6 items. Moreover, an additional one item was included. This barrier scale is rated on a four-point scale (1=no extent, $2=$ to a little extent, $3=$ moderate extent, and $4=$ to a great extent). To identify the relevance of the factors presenting as top barriers, the percentage of respondents choosing the moderate and great extent categories was calculated, then rank-ordered, with 1 representing the top barrier,

The English version of the original developers of the questionnaires was used in this study. The content and cultural sensitivities of the questionnaire were examined. There were four validators; two of them were specialists in the field of nursing education, and the other two were from clinical practice. All four experts agreed that all of the items appear to measure and are appropriate for the topic at hand. The content validity index (CVI) of the EBPQ questionnaire has resulted in 0.88 for relevance and 0.87 for clarity, while the barrier scale has 0.86 for relevance and 0.89 for clarity, which means the questionnaires are highly valid. Prior to using the questionnaires, a pilot test was conducted on 15 nurses. For the EBPQ, it has Cronbach's alpha value of 0.89 and a total Cronbach alpha value of 0.88 for the barrier scale.

\subsection{Data analysis}

SPSS Version 21 (IBM Corp., Armonk, NY, USA) was used to analyze the data. Frequency and percentage were used to determine the demographic information of the staff nurses and barriers to EBP. A t-test was used to compare the gender differences and nationalities, while age, civil status, number of children, highest degree, job title, and years of experience were treated with a one-way analysis of variance (ANOVA).

\subsection{Ethical considerations}

The Ethics Review Board of the Ministry of Health, Hail region, Saudi Arabia, approved this study (number H-2016-0058). Written consent was obtained from the respondents before answering the questionnaires. The researchers explained and informed the participants about the study, expectations, study purpose, risk and benefits, and voluntary participation during the orientation prior to joining the study.

\section{Results}

3.1 Demographic characteristics of nurses

Of the 228 participants, a little over half (55.7\%) belonged to the age group 30-39 years, with $54.5 \%$ females. Over half (55.7\%) of the participants were married, with $45.6 \%$ having no children, and more than half (57\%) were not Saudi nationals. Most of the participants had bachelor's degrees (77.2\%) and belonged to the staff nurse positions (85.1\%). Furthermore, $36.4 \%$ of the participants belonged to the 4-6 years of experience group (Table 1).

\subsection{EBP implementation as perceived by the respondents}

The results of the study showed that the nurses had a positive attitude (15.25), good knowledge (63.44), and good application of EBP (28.02). Overall, the nurses had an outstanding EBP score of 106.73 out of 168 (Table 2).

\subsection{Differences in EBP scores of the respondents across their profile}

Nurses' age $(\mathrm{F}-$ Value $=2.00 ; p=0.11)$, sex $(\mathrm{t}$-value $=-1.82, p=0.70)$ and number of children $(\mathrm{F}-$ value $=1.06 ; p=0.37$ ) were not causal factors for implementing EBP in the workplace. However, civil status $(\mathrm{F}$-value $=3.83 ; p=0.002)$, nationality $(\mathrm{t}$-value $=-1.98 ; p=0.05)$, highest degree $(\mathrm{F}$ - 
value $=4.05, p=<0.001$ ), job title (F-value $=16.38 ; p=<0.001$ ), and years of experience ( $\mathrm{F}$ value $=16.38, p=<0.001$ ) were found significant. Post-hoc Tukey test was conducted on the following demographic factors showing the following results: civil status of participants showed that married nurses scored higher, nationality showed that non-Saudi nurses had better scores, years of experience showed that those with seven years of experience and more scored the highest, job title showed that the title of staff nurse had the lowest score, and highest degree showed that those with master's degrees had a better score (Table 3).

Table 1. Demographic characteristics of nurses $(n=228)$

\begin{tabular}{lcc}
\hline \multicolumn{1}{c}{ Variable } & Frequency & Percentage \\
\hline Age (years old) & 77 & 33.8 \\
$20-29$ & 127 & 55.7 \\
$30-39$ & 21 & 9.2 \\
$40-49$ & 3 & 1.3 \\
$50-59$ & & \\
Gender & 33 & 14.5 \\
Male & 195 & 54.5 \\
Female & & \\
Civil status & 96 & 42.1 \\
Single & 127 & 55.7 \\
Married & 5 & 2.2 \\
Widowed/ Separated & & \\
Number of children & 104 & 45.6 \\
None & 64 & 28.1 \\
1 & 31 & 13.6 \\
2 & 29 & 12.7 \\
3 and above & & \\
Nationality & 98 & 43.0 \\
Saudi & 130 & 57.0 \\
None Saudi & & \\
Highest degree & 38 & 16.7 \\
Diploma & 176 & 77.2 \\
Bachelor & 10 & 4.4 \\
Master & 4 & 1.8 \\
Doctorate & 194 & 85.1 \\
Job title & 21 & 9.2 \\
Staff Nurse & 13 & 5.7 \\
Head Nurse & 19 & 8.3 \\
Supervisor Nurse & 56 & 36.4 \\
Years of experience & 70.7 \\
Less than 1 year & & \\
1-3 years & & 24.6 \\
4-6 years & & \\
7 years and more & & \\
\hline
\end{tabular}

Table 2. EBP implementation score as perceived by the respondents $(n=228)$

\begin{tabular}{lcc}
\hline Variable & Mean & SD \\
\hline Attitudes towards EBP & 15.25 & 5.07 \\
Knowledge of EBP & 63.44 & 19.81 \\
Use of EBP & 28.02 & 6.68 \\
Total & 106.73 & 27.09 \\
\hline
\end{tabular}

3.4 Perceived barriers to evidence-based practice

Table 4 presents the perceived barriers to using EBP. For the organizational factors, the biggest barrier was "Does not have time to read research" (94.3\%), for the communication, the biggest barrier was "Research is not readily available" (97.8\%), and for the adopter, the biggest barrier was "Not capable to evaluate the quality of research" (90.4\%). Lastly, for the innovation, "Uncertain whether to believe results" (68.4\%) was the biggest. 
Table 3. Differences of EBP scores of the respondents across their profile $(n=228)$

\begin{tabular}{lccc}
\hline \multicolumn{1}{c}{ Variable } & Mean \pm SD & Test value & p-value \\
\hline Age & $6.4 \pm 5.02$ & $\mathrm{~F}(2.00)$ & 0.11 \\
Sex & $6.42 \pm 5.02$ & $\mathrm{t}(-1.82)$ & 0.70 \\
Civil Status & $6.1 \pm 3.60$ & $\mathrm{~F}(3.83)$ & $0.002^{*}$ \\
Number of Children & $6.02 \pm 3.62$ & $\mathrm{~F}(1.06)$ & 0.37 \\
Nationality & $5.87 \pm 3.64$ & $\mathrm{t}(-1.98)$ & $0.05^{*}$ \\
Highest Degree & $5.92 \pm 3.64$ & $\mathrm{~F}(4.05)$ & $0.001^{*}$ \\
Job Title & $5.9 \pm 3.65$ & $\mathrm{~F}(16.38)$ & $0.001^{*}$ \\
Years of experience & $5.89 \pm 3.64$ & $\mathrm{~F}(6.21)$ & $0.001^{*}$ \\
\hline Notes. SD=Standard deviation; F=One-way analysis of variance; t=Independent sample t-test; ${ }^{*}$ Significant at 0.05
\end{tabular}

Table 4. Perceived barriers to evidence-based practice $(n=228)$

\begin{tabular}{|c|c|c|c|}
\hline Perceived factors & $\mathrm{f}$ & $\begin{array}{c}\text { Moderate or great } \\
\text { barriers (\%) }\end{array}$ & Rank \\
\hline \multicolumn{4}{|l|}{ Organizational Factors } \\
\hline Insufficient time on the job to implement new ideas & 211 & 92.5 & 6 \\
\hline Does not have time to read research & 215 & 94.3 & 3 \\
\hline Does not have authority to change patient care & 210 & 92.1 & 7 \\
\hline Other staff not supportive of implementation & 107 & 46.9 & 29 \\
\hline Physicians will not cooperate with implementation & 201 & 88.2 & 10 \\
\hline The nurses do not have time to read the research & 213 & 93.4 & 5 \\
\hline Facilities not adequate & 200 & 87.7 & 12 \\
\hline Administration will not allow implementation & 207 & 90.8 & 8 \\
\hline \multicolumn{4}{|l|}{ Communication } \\
\hline Relevant literature not compiled in one place & 195 & $85 \cdot 52$ & 14 \\
\hline Statistical analysis is not understandable & 199 & 87.3 & 13 \\
\hline Research is not readily available & 223 & 97.8 & 1 \\
\hline Research not reported clearly or readably & 214 & 93.9 & 4 \\
\hline Implication for practice not clear & 216 & 94.7 & 2 \\
\hline Research not relevant to nurses practice & 202 & 88.6 & 11 \\
\hline \multicolumn{4}{|l|}{ Adopter } \\
\hline Unaware of research & 190 & 83.3 & 15 \\
\hline Not capable to evaluate the quality of research & 206 & 90.4 & 9 \\
\hline Isolated from knowledgeable colleagues & 189 & 82.9 & 16 \\
\hline Feels benefits of changing practice are minimal & 158 & 69.3 & 19 \\
\hline Unwilling to change/try new ideas & 188 & 82.5 & 17 \\
\hline No documented need to change practice & 175 & 76.8 & 18 \\
\hline Sees little benefit for self & 150 & 65.8 & 21 \\
\hline Does not see the value of research for practice & 149 & 65.4 & 22 \\
\hline \multicolumn{4}{|l|}{ Innovation } \\
\hline Research has not been replicated & 112 & 49.1 & 28 \\
\hline Uncertain whether to believe results & 156 & 68.4 & 20 \\
\hline Literature reports conflicting results & 117 & 51.3 & 27 \\
\hline Research not published fast enough & 128 & 56.1 & 26 \\
\hline Research has methodological inadequacies & 130 & 57.0 & 25 \\
\hline Conclusions drawn from research not justified & 135 & 59.2 & 24 \\
\hline \multicolumn{4}{|l|}{ Additional item } \\
\hline The amount of information is overwhelming & 140 & 61.4 & 23 \\
\hline
\end{tabular}

\section{Discussion}

This study aimed to determine the causal factors that affect the implementation of EBP and its barriers as perceived by nurse practitioners. In this study, nurse practitioners were found to have an outstanding score on EBP; they also showed a positive attitude, good knowledge, and good application. Such findings can be credited to the fact that the nurse practitioners surveyed for this study understood the importance of EBP, acknowledged the need for applying it, and had already started implementing EBP in their daily routine. Indeed, nurses recognize integrating EBP activities into daily clinical care has the potential to increase EBP adoption and involvement. As such, having acknowledged that they have a positive attitude, good knowledge, and good 
application of the EBP allows them to apply credible evidence to particular client situations. These findings are consistent with earlier studies. For example, along with a positive attitude, the participants also had an average level of knowledge (Mehrdad et al., 2012; Panlican et al., 2020). Indeed, in a previous study, it was found that the participants' attitude toward EBP was more positive than their knowledge/skills and adoption of EBP (Shafiei et al., 2014). Similarly, Alqahtani et al. (2020) found that participants in their study obtained average scores on the practice and attitude to EBP.

Nurses' age, sex, and the number of children were not causal factors in implementing EBP in the workplace. In other words, age, gender, and the number of offspring of the participants are not barriers to executing EBP. These factors can be used to strategize to influence the knowledge, attitudes, and practices of nurses towards EBP implementation. In this study, the majority of the respondents were females below the age of 40 years and did not have any children, which, it is believed, did not influence the implementation of EBP. In the study by Fu et al. (2020), it was found that young nurses were much more ready to implement EBP and that they were more than receptive to engaging in new things such as the implementation of EBP. Conversely, evidencebased practice has been reported to practice more by female nurses than male nurses (Aburuz, 2017), and that one of the causal factors that nurses tend to miss out excellence in their practice was dependent on the number of nurses' offspring (Alshammari et al., 2020).

Civil status, nationality, highest degree, job title, and years of experience were found to be the factors towards the implementation of EBP. This means that these factors, once addressed, play a significant role in the success of EBP implementation. In relation to civil status, it could be that married couples have a lifestyle that promotes mutual security and support (Alsaqri et al., 2020), protecting nurses from developing impersonal, cynical, and negative attitudes toward colleagues in the workplace, thus making it a predictor of EBP. Another study similar to this one supports this finding (Cañadas-De la Fuente et al, 2018). The findings of this current study likewise show that nationality predicts the implementation of EBP. This implies that the nationality of the nurses and their values and beliefs are associated with the extent to which EBP is implemented. However, earlier studies have suggested that nurses were acquainted with the EBP concepts irrespective of their role as professional, practice environment, and their nationality. Indeed, regardless of nationality, nurses' implementation of best evidence integrated into their delivery of care stayed mostly primordial (Ammouri et al., 2014; Stokke et al., 2014).

The highest degree or level of education was also found to be a factor in implementing EBP. It was found in this study that nurses with master's degrees scored better. This could be attributed partially to the fact that nurses with higher degrees had greater opportunities to use evidencebased practice in their daily undertakings. However, researchers have suggested lower barriers to the delivery of EBP for nurses with bachelor-level nursing education (Ammouri et al., 2014). Moreover, it has also been found that diploma-nursing degrees do not amply accentuate research procedures and EBP training compared to the bachelor's degree in nursing (Al-Busaidi et al., 2019). Further, lack of exposure to nursing and language of research could also be significant obstacles for nurses in practicing EBP (Novrianda \& Herman, 2019), which can be observed in fresh graduate nurses. In the same way, nurses who had joined EBP training deemed themselves more efficient in incorporating EBP into their practice (Majid et al., 2011). The level of education is an important component in shaping the perception of individuals, including that of nurses. Therefore, a higher level of education results in greater knowledge and skills and the aspiration to apply them at their workplaces (Oyoh et al., 2017).

Results from this study suggest that nurses' years of experience are a factor in the implementation of EBP. This indicates that nurses with more years of experience are expected to implement EBP, credited from their training. Conversely, Al-Busaidi et al. (2019) showed that the utilization of EBP in clinical practice was done less confidently by the new nurses because of their lack of firsthand knowledge. This finding can serve to tailor educational strategies to improve the EBP implementation and utilization for new nurses. Further, the findings of this study indicate that job title could predict the application of EBP. This means that advanced nursing positions such as nurse practitioners, clinical nurse specialists, or nurse educators had substantially greater EBP beliefs and thus greater likelihood of implementing EBP. Nursing mentors, given their longer years of experience and higher levels of education, are linked with higher EBP beliefs and higher chances of implementing EBP (Kim et al., 2016). This highlights the need to focus EBP training on those who are in the beginning stages of their career. 
Concerning barriers to using EBP under the organizational factor, nurses asserted that they have no time to read research. This is because of the nature of their work, where most of the time, nurses were at the bedside and doing documentation. Such a result held true with Thompson et al. (2006) and Mathieson et al. (2019) claiming that the major obstacle to EBP engagement and implementation is the lack of time. The nurse managers in this context need to strategize and look for a way for the nurses to read the research. This study finding indicates a need for support from the managers as this can be a key enabler for nurses to implement evidence-based in their practice. For the communication barriers, nurses reported that research is not readily available. Such a result may be credited to the non-availability of the literature on the internet, and most of the available literature was in abstract form when searched. This result is consistent with the previous finding where published research is not found (Kajermo et al., 1998). Conversely, nurses claimed that they are not capable of evaluating the quality of research. Such a result is possible because the integration of evidence-based practice into the nursing curriculum is still in its early stages, and the majority of the nurses in our study got their EBP information only through their professional development training. In fact, the difficulty of nurses to evaluate the quality of research can be understood from the context or gap in the communication between the academic and practice settings. Indeed, this gap has been identified as a theme from the interdisciplinary barriers that affect the practice of EBP (Shayan et al., 2019). Lastly, nurses were uncertain whether to believe results which made them hesitant to integrate evidence-based in their practice. This result, however, disagrees with Shifaza et al. (2014), where more than half of the participants believed that being uncertain whether to believe results was not a barrier. Overall, the results of EBP barriers highlight the need for administrators and policymakers to recognize that these identified barriers must be a part of nurse's continuing professional development.

\section{Implication and limitation}

The causal factors and barriers from this study point to obstacles that prevent the full and effective implementation of EBP among practicing nurses. This implies that there is an urgent need to identify the needed interventions and tailor them to the requirements of the nurses in a strategic plan for proper and effective implementation of EBP among nurse practitioners in Saudi Arabia. Such a plan, if executed successfully, will provide the nurses the appropriate environment to implement EBP and thereby appreciate and recognize the value of EBP in their daily work. In addition, addressing the factors identified in this study can engage nurse practitioners in research, which will increase their capacity to appraise the value and authenticity of various sources. Further, the findings of this study provide the policymakers with various perspectives to incorporate the essential factors in the early stages of EBP training. Indeed, nursing curriculums can encompass courses that address issues related to EBP.

The researchers acknowledge the limitations of this study in using the purposive sampling method, which may lead to biases and prevent the study results from being generalized. However, this can be addressed by using probability sampling, such as simple random sampling to represent the whole population. Moreover, the use of a self-reported tool in our study could have resulted in a high rating by the participants and thus be biased. It is highly recommended that other methodologies are employed to validate the participants' perceptions.

\section{Conclusion}

Nurses' positive attitude, good knowledge, good application, and outstanding EBP scores are an indication that they are willing to improve their practices in the delivery of safe and quality care. Further, nurses' civil status, nationality, highest degree, job title, and years of experience were causal factors to EBP but with weak influence. Moreover, considering that communication was the most perceived barrier to EBP, it can impact the effective implementation of EBP greatly. Nurses in the hospital practice should continuously undergo training to be able to use EBP effectively. A training program focusing on the married nurses and staff nurses as well as strengthening the communication characteristics to promote the EBP is recommended. For instance, some training programs or strategies such as mentor-mentee programs, communications to colleagues, and interactive education can help in the EBP application. The effectiveness of the training program can be assessed in the future study using different research designs. 


\section{Acknowledgment}

This study was a result of the mentor-mentee program of the Nurse Educators and Practitioners Guild (NEPraGuild, Inc).

\section{Author contribution}

MA, RHA, and GA were responsible for the study conceptualization and study design, while MA, HA, and SA were responsible for the acquisition of data. RDD and MA analyzed and interpreted the data. All of the authors drafted the manuscript and critically revised it. Further, all authors give final approval of the version submitted in this journal.

\section{Conflict of interest}

The authors declare no conflicts of interest.

\section{References}

AbuRuz, M. E., Hayeah, H. A., Al-Dweik G., \& Al-Akash, H. Y. (2017). Knowledge, attitudes, and practice about evidence-based practice: A Jordanian study. Health Science Journal, 11(2), 489. https://doi.org/10.21767/1791-809X.1000489

Al-Busaidi, I. S., Al Suleimani, S. Z., Dupo, J. U., Al Sulaimi, N. K., \& Nair, V. G. (2019). Nurses' knowledge, attitudes, and implementation of evidence-based practice in Oman: A multiinstitutional, cross-sectional study. Oman Medical Journal, 34(6), 521-527. https://doi.org/10.5001/omj.2019.95

Alsaqri S. H., Pasay-an, E., Villacorte, L., Madjid, F., Pacis, C., \& Al-Sadi, A. K. A. (2020). Organizational empowerment among nursing faculty in the northwestern region of Saudi Arabia. Makara Journal Health Research, 24(2), 114-120. https://doi.org/10.7454/msk.v24i2.1205.

Alshammari, M. H., Pacheco, H., Pasay-an, E., Alshammari, F., Alsharari, A., Felemban, E., \& Dayrit, R. D. (2020). Nurses perspectives on the degree of missed nursing care in the public hospitals in Hail City, Kingdom of Saudi Arabia. Belitung Nursing Journal, 6(6), 190-195. https://doi.org/10.33546/bnj.1233

Alqahtani N, Oh K.M., Kitsantas P., \& Rodan, M. (2020). Nurses' evidence-based practice knowledge, attitudes and implementation: A cross-sectional study. Journal of Clinical Nursing, 29(1-2): 274-283. https://doi.org/10.1111/jocn.15097

Ammouri, A. A., Raddaha, A. A., Dsouza, P., Geethakrishnan, R., Noronha, J. A., Obeidat, A. A., \& Shakman, L. (2014). Evidence-based practice: Knowledge, attitudes, practice and perceived barriers among nurses in Oman. Sultan Qaboos University Medical Journal, 14(4), e537e545.

Cañadas-De la Fuente, G. A., Ortega, E., Ramirez-Baena, L., De la Fuente-Solana, E. I., Vargas, C., \& Gómez-Urquiza, J. L. (2018). Gender, marital status, and children as risk factors for burnout in nurses: A meta-analytic study. International Journal of Environmental Research and Public Health, 15(10). https://doi.org/10.3390/ijerph15102102

Chien, L-Y. (2019). Evidence-based practice and nursing research. Journal of Nursing Research, 27(4), e29. https://doi.org/10.1097/jnr.0000000000000346

Chummum, H., \& Tiran, D. (2008). Increasing research evidence in practice: A possible role for the consultant nurse. Journal of Nursing Management, 16(3), 327-333. https://doi.org/10.1111/j.1365-2834.2007.00791.x

Dalheim, A., Harthug, S., Nilsen, R. M., \& Nortvedt, M. W. (2012). Factors influencing the development of evidence-based practice among nurses: A self-report survey. BMC health Services Research, 12, 367. https://doi.org/10.1186/1472-6963-12-367

Farokhzadian, J., Khajouei, R., \& Ahmadian, L. (2015). Evaluating factors associated with implementing evidence-based practice in nursing. Journal of Evaluation in Clinical Practice, 21(6), 1107-1113. https://doi.org/10.1111/jep.12480

Fu, L., Su, W., Ye, X., Li, M., Shen, J., Chen, C., Guo, Q., Ye, L., \& He, Y. (2020). Evidence-based practice competency and related factors among nurses working in public hospitals. INQUIRY: A Journal of Medical Care Organization, Provision and Financing, 57, 46958020927876. https://doi.org/10.1177/0046958020927876 
Funk, S. G., Champagne, M. T., Wiese, R. A., \& Tornquist, E. M. (1991). BARRIERS: The barriers to research utilization scale. Applied Nursing Research, 4(1), 39-45. https://doi.org/10.1016/s0897-1897(05)80052-7

Harper, M. G., Gallagher-Ford, L., Warren, J. I., Troseth, M., Sinnott, L. T., \& Thomas, B. K. (2017). Evidence-based practice and U.S. healthcare outcomes: Findings from a national survey with nursing professional development practitioners. Journal for Nurses in Professional Development, $33(4), \quad 170-179$. https://doi.org/10.1097/NND.0000000000000360

Kajermo, K. N, Nordström, G., Krusebrant, A., \& Björvell, H. (1998). Barriers to and facilitators of research utilization, as perceived by a group of registered nurses in Sweden. Journal of Advanced Nursing, 27(4), 798-807. https://doi.org/10.1046/j.1365-2648.1998.00614.x

Kim, S. C., Stichler, J. F., Ecoff, L., Brown, C. E., Gallo, A. M., \& Davidson, J. E. (2016). Predictors of evidence-based practice implementation, job satisfaction, and group cohesion among regional fellowship program participants. Worldviews on Evidence-Based Nursing, 13(5), 340-348. https://doi.org/10.1111/wvn.12171

Khammarnia, M., Haj Mohammadi, M., Amani, Z., Rezaeian, S., \& Setoodehzadeh, F. (2015). Barriers to implementation of evidence based practice in zahedan teaching hospitals, Iran, 2014. Nursing Research and Practice, 2015, 357140. https://doi.org/10.1155/2015/357140.

Majid, S., Foo, S., Luyt, B., Zhang, X., Theng, Y. L., Chang, Y. K., \& Mokhtar, I. A. (2011). Adopting evidence-based practice in clinical decision making: Nurses' perceptions, knowledge, and barriers. Journal of the Medical Library Association, 99(3), 229-236. https://doi.org/10.3163/1536-5050.99.3.010

Malik, G., McKenna, L., \& Plummer, V. (2015). Perceived knowledge, skills, attitude and contextual factors affecting evidence-based practice among nurse educators, clinical coaches and nurse specialists. International Journal of Nursing Practice, 21(2), 46-57 https://doi.org/10.1111/ijn.12366

Mallion, J., \& Brooke, J. (2016). Community- and hospital-based nurses' implementation of evidence-based practice: Are there any differences? British Journal of Community Nursing, 21(3), 148-154. https://doi.org/10.12968/bjcn.2016.21.3.148

Mathieson, A., Grande, G., \& Luker, K. (2019). Strategies, facilitators and barriers to implementation of evidence-based practice in community nursing: A systematic mixedstudies review and qualitative synthesis. Primary Health Care Research \& Development, 20, e6. https://doi.org/10.1017/S1463423618000488

Mehrdad, N., Joolaee, S., Joulaee, A., \& Bahrani, N. (2012). Nursing faculties' knowledge and attitude on evidence-based practice. Iranian Journal of Nursing and Midwifery Research, $17(7), 506-511$.

Melnyk, B.M., \& Fineout-Overholt, E. (2015). Evidence-based practice in nursing \& healthcare. A guide to best practice. 3 rd ed. Wolters Kluwer.

Melnyk, B. M., Fineout-Overholt, E., Gallagher-Ford, L., \& Kaplan, L. (2012). The state of evidence-based practice in US nurses: Critical implications for nurse leaders and educators. The Journal of Nursing Administration, 42(9), 410-417. https://doi.org/10.1097/NNA.obo13e3182664eoa

Novrianda, D., \& Herman, H. (2019). Knowledge, attitude and practice of evidence-based nursing practice and barriers. Journal Keperawatan Padjadjaran, 7(3), 236-245. https://doi.org/10.24198/jkp.v7i3.884.g236

Oyoh, O., Somantri, I., \& Sekarwana, N. (2017). Pengalaman perawat dalam pelaksanaan sistem pemberian pelayanan keperawatan profesional di RSUD Cibabat: Studi fenomenologi. [Nurses' experiences in the implementation of professional nursing services system in Cibabat general hospital: A Phenomenological study]. Jurnal Keperawatan Padjadjaran, 5(3), 329-339. https://doi:10.24198/jkp.v5i3.678

Ozdemir, L., \& Akdemir N. (2009). Turkish nurses' utilization of research evidence in clinical practice and influencing factors. International Nursing Review, 56(3), 319-325. https://doi:10.1111/j.1466-7657.2009.00707.x.

Panlican A. S., Pasay-an, E. A., Gonzales, F. M., Alreshidi, M. S., Ibno, N. L., \& Alenzi S. S. (2020). A survey on the knowledge and attitude on pain management among nurses employed in the government hospitals. Saudi Journal for Health Sciences, 9(2), 97-101. https://doi.org/10.4103/sjhs.sjhs_100_20 
Raosoft, I. (2004). Raosoft sample size calculator. http://www.raosoft.com/samplesize.html

Renolen, A., Hoye, S., Hjalmhult, E., Dabolt, L. J., \& Kirkevold, M. (2018). "Keeping on track"hospital nurses' struggles with maintaining workflow while seeking to integrate evidencebased practice into their daily work: A grounded theory study. International Journal of Nursing Studies, 77, 179-188. https://doi.org/10.1016/j.ijnurstu.2017.09.006

Sackett, D. L., Straus, S. E., Richardson, W. S., Rosenberg, W., \& Haynes, R. B. (2000). Evidencebased medicine: How to practice and teach EBM. 2nd ed. Churchill-Livingstone.

Saunders, H., Stevens, K. R., \& Vehviläinen-Julkunen, K. (2016). Nurses' readiness for evidencebased practice at Finnish university hospitals: A national survey. Journal of Advance Nursing, 72(8), 1863-1874. https://doi:10.1111/jan.12963.

Shafiei, E., Baratimarnani, A., Goharinezhad, S., Kalhor, R., \& Azmal, M. (2014). Nurses' perceptions of evidence-based practice: A quantitative study at a teaching hospital in Iran. Medical Journal of the Islamic Republic of Iran, 28, 135.

Shayan, S. J., Kiwanuka, F., \& Nakaye, Z. (2019). Barriers associated with evidence-based practice among nurses in low- and middle-income countries: A systematic review. Worldviews on Evidence-Based Nursing, 16(1), 12-20. https://doi.org/10.1111/wvn.12337

Shifaza, F., Evans,D., \& Bradley,H. (2014). Nurses' perceptions of barriers and facilitators to implement EBP in the Maldives. Advances in Nursing, 2014, Article ID 698604. https://doi.org/10.1155/2014/698604

Stokke, K., Olsen, N. R., Espehaug, B., \& Nortvedt, M. W. (2014). Evidence based practice beliefs and implementation among nurses: A cross-sectional study. BMC Nursing, 13, 8. https://doi.org/10.1186/1472-6955-13-8

Swito, I., Sidin, A. I., \& Rachmawaty, R. (2021). Factors related to the implementation of evidenced-based practice (EBP) of nursing staffing levels in hospitals: A literature review. Journal of Asian Multicultural Research for Medical and Health Science Study, 2(1), 60-68. https://doi.org/10.47616/jamrmhss.v2i1.88

Thompson, D. R., Chau, J. P. C., \& Lopez, V. (2006). Barriers to, and facilitators of, research utilisation: A survey of Hong Kong registered nurses. International Journal of EvidenceBased Healthcare, 4(2), 77-82. https://doi.org/10.1111/j.1479-6988.2006.00036.x

Upton, D., \& Upton, P. (2006). Development of an evidence-based practice questionnaire for nurses. Journal of Advance Nursing, 53(4), 454-458. https://doi:10.1111/j.13652648.2006.03739.x 